\title{
Comparative effectiveness of triple therapy versus dual bronchodilation in COPD
}

Jaco Voorham¹, Massimo Corradi², Alberto Papi (ib ${ }^{3}$, Claus F. Vogelmeier ${ }^{4}$, Dave Singh ${ }^{5}$, Leonardo M. Fabbri $\mathbb{1}^{3,6}$, Marjan Kerkhof ${ }^{1}$, Janwillem H. Kocks ${ }^{1,7}$, Victoria Carter ${ }^{1}$ and David Price $\mathbb{1}^{1,8}$

Affiliations: ${ }^{1}$ Observational and Pragmatic Research Institute, Singapore, Singapore. ${ }^{2}$ Dept of Medicine and Surgery, University Hospital of Parma, Parma, Italy. ${ }^{3}$ Dept of Medical Sciences, University of Ferrara, Ferrara, Italy. ${ }^{4}$ Dept of Internal Medicine, Pulmonary and Critical Care Medicine, University of Marburg, Member of the German Centre for Lung Research (DZL), Marburg, Germany. ${ }^{5}$ University of Manchester, Manchester University NHS Foundation Trust, Manchester, UK. ${ }^{6}$ COPD Center, Institute of Medicine, Sahlgrenska University Hospital, University of Gothenburg, Gothenburg, Sweden. ${ }^{7}$ General Practitioners Research Institute, Groningen, The Netherlands. ${ }^{8}$ Centre of Academic Primary Care, Division of Applied Health Sciences, University of Aberdeen, Aberdeen, UK.

Correspondence: David B. Price, Academic Primary Care, Division of Applied Health Sciences, University of Aberdeen, Polwarth Building, Foresterhill, Aberdeen AB25 2ZD, UK. E-mail: dpricedopri.sg

ABSTRACT This real-world study compared the effectiveness of triple therapy (TT; long-acting muscarinic antagonists (LAMAs)/long-acting inhaled $\beta$-agonists (LABAs)/inhaled corticosteroids (ICSs)) versus dual bronchodilation (DB; LAMAs/LABAs) among patients with frequently exacerbating COPD. A matched historical cohort study was conducted using United Kingdom primary care data. Patients with COPD aged $\geqslant 40$ years with a history of smoking were included if they initiated TT or DB from no maintenance/LAMA therapy and had two or more exacerbations in the preceding year. The primary outcome was time to first COPD exacerbation. Secondary outcomes included time to treatment failure, first acute respiratory event, and first acute oral corticosteroid (OCS) course. Potential treatment effect modifiers were investigated. In 1647 matched patients, initiation of TT reduced exacerbation risk (adjusted hazard ratio (HR) $0.87,95 \%$ CI $0.76-0.99$ ), risk of acute respiratory event (HR $0.74,95 \%$ CI $0.66-0.84$ ) and treatment failure (HR $0.83,95 \%$ CI $0.73-0.95$ ) compared with DB. Risk reduction for acute respiratory events was greater for patients with higher rates of previous exacerbations. At baseline blood eosinophil counts $(\mathrm{BECs}) \geqslant 0.35 \times 10^{9}$ cells $\cdot \mathrm{L}^{-1}$, TT was associated with lower risk of OCS prescriptions than DB. This study provides real-life evidence of TT being more effective in reducing exacerbation risk than DB, which became more accentuated with increasing BEC and previous exacerbation rate.

@ERSpublications

In a real-world population of COPD patients with history of exacerbations, initiation of triple therapy was associated with a larger reduction in future risk of exacerbation, acute respiratory event, and treatment failure compared with dual bronchodilation http://bit.ly/2xA1Xut

Cite this article as: Voorham J, Corradi M, Papi A, et al. Comparative effectiveness of triple therapy versus dual bronchodilation in COPD. ERJ Open Res 2019; 5: 00106-2019 [https://doi.org/10.1183/ 23120541.00106-2019].

This article has supplementary material available from openres.ersjournals.com

Received: April 302019 | Accepted after revision: May 282019

Copyright $\odot E R S$ 2019. This article is open access and distributed under the terms of the Creative Commons Attribution Non-Commercial Licence 4.0. 


\section{Introduction}

Chronic obstructive pulmonary disease (COPD) is characterised by persistent and progressive airflow limitation with a proportion of patients suffering from exacerbations of the disease [1]. The mainstay of therapeutic management in COPD are long-acting inhaled bronchodilators, either long-acting muscarinic antagonists (LAMAs) or long-acting inhaled $\beta$-agonists (LABAs), with the primary aim of reducing symptoms and exacerbations while improving wellbeing [2]. A combination of LAMAs/LABAs is recommended in patients where disease control is not satisfactory using long-acting bronchodilator monotherapy, and inhaled corticosteroids (ICSs) can be added for triple therapy (TT; ICS plus LAMA plus LABA) for those with persisting exacerbations [2]. However, ICS use has been associated with an increased risk of adverse events, including pneumonia [3], bone fracture, and skin thinning/easy bruising [4]. ICS therapy is widely prescribed in clinical practice in patients with $\operatorname{COPD}[5,6]$.

TT has been shown to be more effective than an ICS/LABA combination for the treatment of COPD [7, 8]. Recent randomised controlled clinical trials (RCTs) support the efficacy of TT compared with dual bronchodilation (DB) with LAMAs/LABAs in selected populations $[9,10]$. In addition, a higher blood eosinophil count (BEC) in patients with COPD has been associated with an increased benefit from ICSs in terms of exacerbation reduction [11]. There has been a call for representative, longer-term studies to determine the potential benefits of TT versus DB therapy, to improve the evidence which informs real-life prescribing decisions $[12,13]$. This study aims to compare the real-world effectiveness of TT versus DB in the treatment of patients with frequently exacerbating COPD and to explore the potential heterogeneity of the effectiveness driven by patient and therapy characteristics.

\section{Methods}

\section{Study design and data sources}

A matched historical cohort study was conducted on patients with COPD in the United Kingdom (UK). Data were extracted from two databases: the Optimum Patient Care Research Database (OPCRD; https:// opcrd.co.uk/) and the Clinical Practice Research Datalink (CPRD; www.cprd.com/). The OPCRD contains anonymised, longitudinal medical record data for over 5 million patients from 650 primary care practices. It is a high-quality data source used regularly in clinical, epidemiological, and pharmaceutical research [14, 15]. The CPRD contains anonymised primary care data for 5 million patients from $>600$ general practices in the UK. The overlap in practices covered by these two databases is $<5 \%$. To maximise the sample size, data were extracted from both the OPCRD and CPRD for patients who stepped-up between 2003 and 2017 from no prior maintenance therapy or LAMA monotherapy for COPD, to either DB or TT. Data were combined, and duplicates were removed. The data extracted included demographic and clinical characteristics, prescriptions, and data on comorbidities.

The quality of some data is driven by the Quality and Outcomes Framework (QOF) in the UK including diagnostic and annual spirometry and mMRC recording [16]. The clinical data are mostly recorded using read codes, and the QOF requires spirometry to confirm the COPD diagnostic read codes in the UK. The diagnosis of COPD in CPRD has been validated [17].

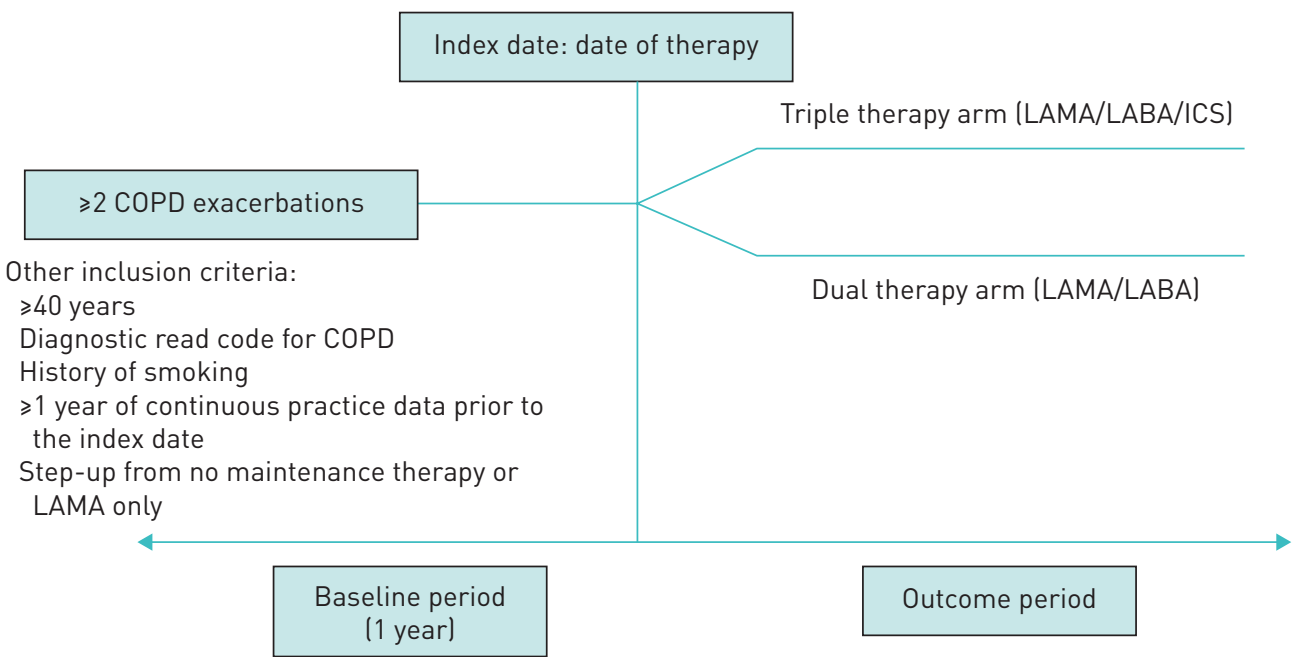

FIGURE 1 Study design. ICS: inhaled corticosteroid; LABA: long-acting inhaled B-agonist; LAMA: long-acting muscarinic antagonist. 
This study included a 1-year baseline period preceding the index date, and an outcome period after the index date, ending at the last date of data extraction or patient deregistration (figure 1). The index date was defined as the date of therapy step-up. Patients were divided into the following two cohorts (exposure groups): patients initiating TT (LAMAs/LABAs/ICSs) and patients initiating DB therapy (LAMAs/LABAs) without ICSs, both from prior no maintenance therapy or LAMA monotherapy. Patients on all inhaler combinations of the treatments under study were included. To avoid the inclusion of patients under DB treatment who recently stopped ICSs, patients were excluded if they had been treated with ICSs in the 12 months prior to the index date. This exclusion was conducted because stepping down ICSs could potentially bias the results in favour of TT.

\section{Study population}

Patients who met the following criteria were eligible for inclusion: a diagnostic read code for COPD, aged $\geqslant 40$ years, history of smoking, had $\geqslant 1$ year of continuous data prior to the index date (baseline year), and $\geqslant 2$ moderate/severe exacerbations in the baseline year. The exclusion criteria included active asthma at or after the index date (defined as $\geqslant 1$ diagnostic read code for asthma or $\geqslant 1$ asthma monitoring or review read code recorded on or after the index date), a diagnostic code for asthma-COPD overlap syndrome, and a diagnostic code ever for other chronic lower respiratory conditions. All code lists are available from the study authors.

\section{Study outcomes}

The primary outcome was the time to first COPD exacerbation to avoid the exclusion of patients who were lost to follow-up from the analyses. Secondary outcomes included time to first acute respiratory event, time to treatment failure, time to first acute oral corticosteroid (OCS) course, time to first antibiotic prescription with evidence of a lower respiratory primary care consultation, modified Medical Research Council (mMRC) dyspnoea score within 18 months after the index date, time to first pneumonia diagnosis, and the number of occurrences in the first year of the outcome period of the following: exacerbations, acute OCS courses, antibiotic prescriptions with evidence of a lower respiratory primary care consultation and acute respiratory events. Definition of study outcomes are listed in table 1.

\section{TABLE 1 Study outcomes and definitions}

\section{Primary}

1) Time to first exacerbation

Respiratory-related hospital attendance/admission AND/OR

Respiratory-related emergency room attendance AND/OR

Prescription of acute OCS course AND/OR

Antibiotics prescribed with evidence of lower respiratory consultation on the same day

\section{Secondary}

2) Time to first acute respiratory event

Respiratory-related consultation, not for annual monitoring review

3) Time to treatment failure

Prescription of additional chronic therapy (theophylline or other methylxanthines); maintenance OCS; PDE4 inhibitor; macrolides (e.g. azithromycin, erythromycin); mucolytics (e.g. carbocysteine, $\mathrm{N}$-acetylcysteine); LTRA (nedocromil) AND/OR

An exacerbation (as defined above)

4) Time to first acute OCS course

5) Time to first antibiotics prescription with evidence of lower respiratory consultation, to avoid misclassification of antibiotics being prescribed for another reason [18]

Number of occurrences in the first 1-year outcome period of:

6) Exacerbations

7) Acute OCS courses

8) Antibiotic prescriptions with evidence of lower respiratory consultation

9) Acute respiratory events

10) mMRC score within 18 months after index date; $\geqslant 2$ versus $<2$

11) Time to first pneumonia diagnosis

Chest radiography AND/OR

Diagnostic code

OCS: oral corticosteroid; PDE: phosphodiesterase; LTRA: leukotriene receptor antagonist; mMRC: modified Medical Research Council dyspnoea scale. 


\section{Data analysis}

All data were analysed using Stata MP/6 version 15.1 (StataCorp, College Station, TX, USA). The number of clinical events or measurements occurring at the index date were included in the baseline characterisation, however, prescriptions of drugs at the index date were not included. Standardised mean difference (SMD) was used to quantify differences in both continuous and categorical variables between the treatment cohorts at baseline. An SMD $\leqslant 10 \%$ indicated sufficient balance between treatment cohorts. The p-values were also reported for differences at baseline using Pearson's Chi-squared test for categorical variables and the Kruskal-Wallis equality-of-populations rank test for variables on a continuous or ordinal scale. Binary and categorical variables were summarised with frequencies and percentages, whereas distributions and descriptive statistics of central tendency (medians and means) and dispersion (SD and interquartile range) were produced for quantitative variables.

Patients in the DB and TT cohorts were propensity score matched to account for potential biases, such as indication bias, where different treatment combinations could be selected for patients with different disease severity. A propensity score was created using a logistic regression model including all baseline variables $[19,20]$. The cohorts were matched 1 to 3 without replacement using nearest neighbour calliper matching. After matching, the SMD was recalculated to verify the accuracy of the propensity score model. To assess the robustness of findings with regards to potential restriction of the study population due to the matching, the inverse probability of treatment weighting (IPTW) approach, which uses all available patients, was used for sensitivity analyses.

The follow-up duration was summarised and the unadjusted incidence rate for each outcome per patient-year of follow-up time was calculated for the treatment cohorts. To compare the incidence rate per outcome between the treatment cohorts, unadjusted incidence rate ratios (IRRs) with $95 \%$ confidence intervals (CI) were calculated.

The proportion of patients improving, remaining unchanged, and worsening from the 1-year baseline to the first year of the outcome period in terms of the number of outcome events of interest was calculated, and a number needed to benefit (NNB) was derived from these values. NNB provides a measure for the benefit of a treatment while also taking account of the patients who remained unchanged and worsened due to the treatment [21]. For this specific analysis, only patients with $\geqslant 1$ year of follow-up were included.

The start of follow-up for each patient was their index date. The end of follow-up was defined as the earliest date at which the patient developed the outcome of interest, transferred out of the practice, died, or the date of the practice's last data collection. A time-to-event analysis was performed to estimate the association between treatment and time to first outcome event with right censoring at loss to follow-up. Stratified Cox regression was used to estimate hazard ratios (HRs) of the treatment effect for each outcome, adjusted for any residual confounders following matching. Holm's method was used to indicate which of the 10 secondary outcomes were significant after adjustment for multiple testing [22]. The proportional hazard assumption was evaluated visually by means of a $\log -\log$ plot of survival. Conditional negative binomial regression was used to compare count outcomes, and conditional logistic regression was used to compare binary outcomes. Residual confounders were selected by assessing their bias potential, the relative change in the coefficient resulting from their addition to the model predicting the outcome of interest. A coefficient change of $\geqslant 2 \%$ designated the variable as a confounder. See supplementary table 1 for the covariates identified as showing residual confounding and used to adjust for in the multivariable models in the matched cohort. A p-value $<0.05$ was considered statistically significant. An intention-to-treat design was used, thus allowing patients in the two treatment cohorts to change their therapy during follow-up, without being censored or otherwise removed from the analyses. A sensitivity analysis excluding patients with a history of asthma prior to the index date was carried out post hoc to confirm that any effect seen was not due to asthma.

To assess the effect modification, an interaction term between treatment and candidate modifiers (number of exacerbations, most recent BEC, level of airflow limitation, GOLD risk group, and number of nonrespiratory drugs prescribed in baseline year) was added to the models adjusted for confounders. For the time to pneumonia diagnosis, the effect modification could not be assessed due to a small number of events. Results were presented for the other 10 outcomes. Holm's method was used to indicate which outcomes were significant after adjustment for multiple testing for each candidate modifier separately (10 tests). Patients were categorised into a GOLD risk group based on their mMRC score. We selected the mMRC score instead of the COPD Assessment Test score as we previously observed mMRC to be more conservative in classifying patients into GOLD risk groups [23].

\section{Results}

There were 1181 patients with 2864 patient-years of follow-up in the TT arm and 466 patients with 1090 patient-years of follow-up in the DB arm. For a flow diagram of patient selection see figure 2. The 
demographic and clinical characteristics of matched patients are presented in table 2 and supplementary table 2. Over $90 \%(72 / 77)$ characteristics were well balanced between the matched cohorts, indicated by SMD $<10 \%$. The mean age of patients in both treatment cohorts was 69 years and about half were male. Nearly half of the patients had an mMRC score between 2-4, corresponding to GOLD group D. The number of nonreliever drugs taken by patients at baseline is presented in supplementary table 3 . Following matching, the number of nonreliever drugs were balanced between the TT arm and the DB arm. Almost half of the DB-initiating patients did not change their therapy for the duration of their follow-up; this was the case for $58 \%$ of TT initiators (Supplementary Table 4). See Supplementary Table 5 for baseline characteristics of the unmatched cohorts.

Patients in both arms showed great improvement in the number of exacerbations, acute respiratory events, acute OCS courses, and antibiotics courses from the baseline 1-year period to the first year of follow-up period. The proportion of patients who showed an improvement in the number of exacerbations, acute respiratory events, and acute OCS courses were higher for those initiating TT compared with patients initiating DB (table 3). The proportion of patients worsening was mostly lower for TT. This resulted in the number of patients needed to benefit from TT ranging 10-21 for these outcomes, and higher for the number of antibiotics courses (134). These statistics were similar to the unmatched cohort (data not shown).

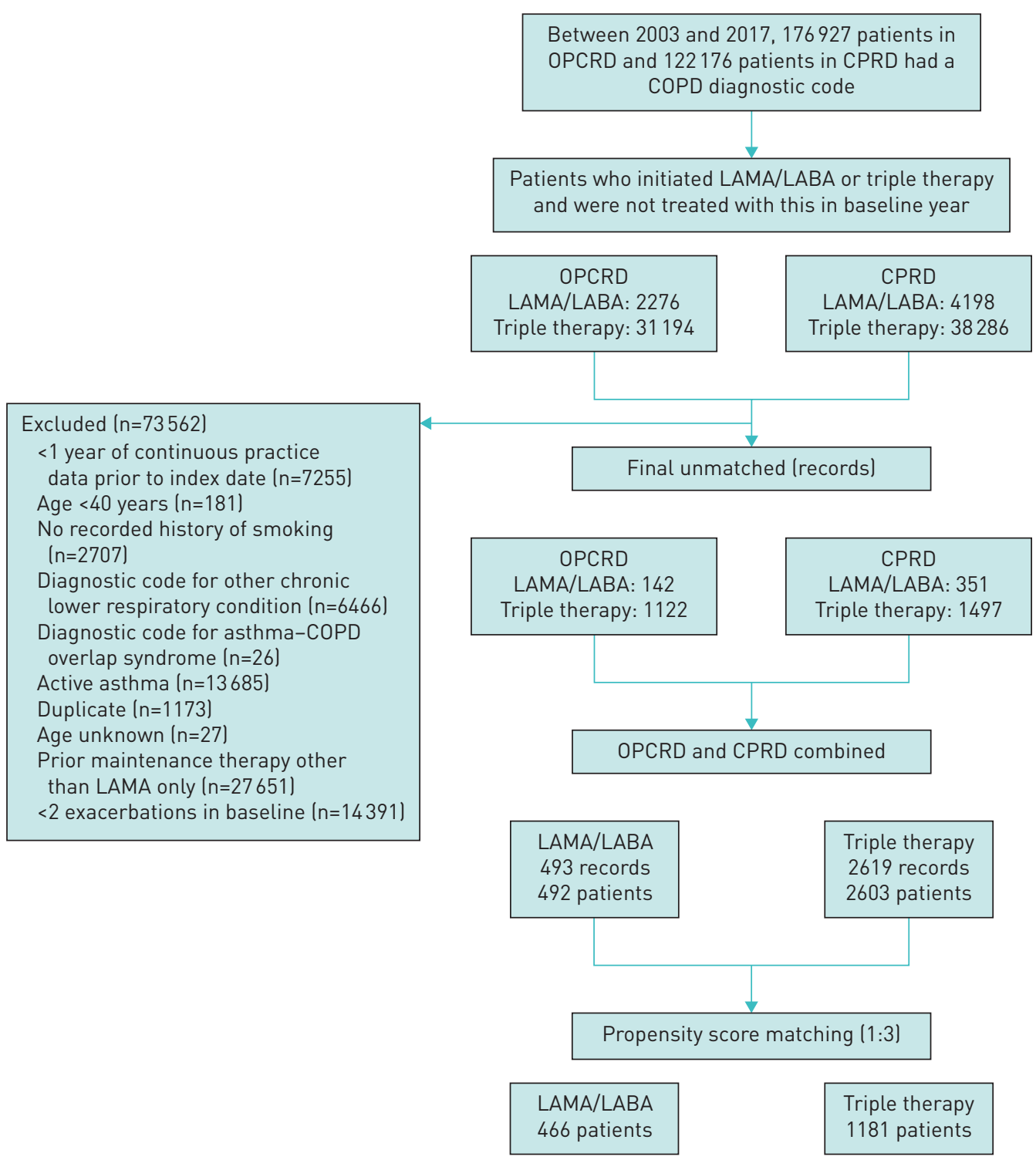

FIGURE 2 Flow diagram of patient selection. CPRD: Clinical Practice Research Datalink; LABA: long-acting inhaled B-agonist; LAMA: long-acting muscarinic antagonist; OPCRD: Optimum Patient Care Research Database. 


\section{TABLE 2 Patient baseline characterisation, matched}

\begin{tabular}{|c|c|c|c|c|}
\hline & LAMA/LABA ( $n=466)$ & $\begin{array}{l}\text { Triple therapy } \\
\text { (n=1181) }\end{array}$ & $\mathrm{p}$-value & SMD \\
\hline Age years & $69.2 \pm 10.7 / 70.0(15.0)$ & $69.4 \pm 10.2 / 69.0(14.0)$ & 0.672 & 2.0 \\
\hline$\geqslant 40-<60$ years & $92(19.7 \%)$ & $194(16.4 \%)$ & 0.278 & 6.8 \\
\hline$\geqslant 60-<80$ years & $295(63.3 \%)$ & $778(65.9 \%)$ & & \\
\hline$\geqslant 80$ years & $79(17.0 \%)$ & $209(17.7 \%)$ & & \\
\hline Males & $233(50.0 \%)$ & $603(51.1 \%)$ & 0.699 & 2.1 \\
\hline Index year & $2013.2 \pm 3.4 / 2014.0$ (5.0) & $2012.5 \pm 2.9 / 2013.0(4.0)$ & $<0.001$ & 21.8 \\
\hline BMI n (\% nonmissing) & $463(99.4 \%)$ & $1167(98.8 \%)$ & 0.506 & 7.5 \\
\hline$<18.5 \mathrm{~kg} \cdot \mathrm{m}^{-2}$ & $22(4.8 \%)$ & $69(5.9 \%)$ & & \\
\hline$\geqslant 18.5-<25 \mathrm{~kg} \cdot \mathrm{m}^{-2}$ & $145(31.3 \%)$ & $397(34.0 \%)$ & & \\
\hline$\geqslant 25-<30 \mathrm{~kg} \cdot \mathrm{m}^{-2}$ & $159(34.3 \%)$ & $376(32.2 \%)$ & & \\
\hline$\geqslant 30 \mathrm{~kg} \cdot \mathrm{m}^{-2}$ & $137(29.6 \%)$ & $325(27.8 \%)$ & & \\
\hline \multicolumn{5}{|l|}{ Current smoker } \\
\hline No & $256(54.9 \%)$ & $653(55.3 \%)$ & 0.896 & 0.7 \\
\hline Yes & $210(45.1 \%)$ & $528(44.7 \%)$ & & \\
\hline Asthma diagnosis, ever & $38(8.2 \%)$ & $153(13.0 \%)$ & 0.006 & 15.7 \\
\hline \multicolumn{5}{|l|}{ Charlson Comorbidity Index } \\
\hline$\leqslant 1$ & $333(71.5 \%)$ & $845(71.5 \%)$ & 0.999 & 0.1 \\
\hline $2-4$ & $76(16.3 \%)$ & $190(16.1 \%)$ & & \\
\hline $5-9$ & $26(5.6 \%)$ & $67(5.7 \%)$ & & \\
\hline$\geqslant 10$ & $31(6.7 \%)$ & $79(6.7 \%)$ & & \\
\hline $\begin{array}{l}\text { Blood eosinophil count } \mathrm{n} \\
\text { (\% nonmissing) }\end{array}$ & $391(83.9 \%)$ & $983(83.2 \%)$ & 0.808 & 2.2 \\
\hline$<0.05 \times 10^{9}$ cells per $L$ & $8(2.0 \%)$ & $31(3.2 \%)$ & & \\
\hline $0.05-0.14 \times 10^{9}$ cells per $L$ & $110(28.1 \%)$ & $267(27.2 \%)$ & & \\
\hline $0.15-0.24 \times 10^{9}$ cells per $L$ & $110(28.1 \%)$ & $281(28.6 \%)$ & & \\
\hline $0.25-0.34 \times 10^{9}$ cells per $L$ & $80(20.5 \%)$ & $187(19.0 \%)$ & & \\
\hline $0.3-0.44 \times 10^{9}$ cells per $L$ & $27(6.9 \%)$ & $86(8.7 \%)$ & & \\
\hline $0.4-0.54 \times 10^{9}$ cells per $L$ & $23(5.9 \%)$ & $54(5.5 \%)$ & & \\
\hline $0.5-0.64 \times 10^{9}$ cells per $L$ & $10(2.6 \%)$ & $30(3.1 \%)$ & & \\
\hline$\geqslant 0.65 \times 10^{9}$ cells per $L$ & $23(5.9 \%)$ & $47(4.8 \%)$ & & \\
\hline \multicolumn{5}{|l|}{ SABA prescriptions } \\
\hline 0 & $63(13.5 \%)$ & $237(20.1 \%)$ & 0.021 & 8.1 \\
\hline $1-2$ & $103(22.1 \%)$ & $235(19.9 \%)$ & & \\
\hline $3-5$ & $100(21.5 \%)$ & $220(18.6 \%)$ & & \\
\hline $6-9$ & $108(23.2 \%)$ & $241(20.4 \%)$ & & \\
\hline$\geqslant 10$ & $92(19.7 \%)$ & $248(21.0 \%)$ & & \\
\hline \multicolumn{5}{|c|}{ Salbutamol-equivalent average daily } \\
\hline SABA dose & & & & \\
\hline $0 \mu \mathrm{g}$ & $63(13.5 \%)$ & $237(20.1 \%)$ & 0.033 & 8.9 \\
\hline $1-100 \mu \mathrm{g}$ & $48(10.3 \%)$ & $110(9.3 \%)$ & & \\
\hline $101-200 \mu \mathrm{g}$ & $83(17.8 \%)$ & $189(16.0 \%)$ & & \\
\hline $201-300 \mu \mathrm{g}$ & $58(12.4 \%)$ & $110(9.3 \%)$ & & \\
\hline $301-400 \mu \mathrm{g}$ & $41(8.8 \%)$ & $102(8.6 \%)$ & & \\
\hline$>400 \mu \mathrm{g}$ & $173(37.1 \%)$ & $433(36.7 \%)$ & & \\
\hline \multicolumn{5}{|l|}{ SAMA prescriptions } \\
\hline 0 & $415(89.1 \%)$ & $1044(88.4 \%)$ & 0.982 & 1.6 \\
\hline 1 & $11(2.4 \%)$ & $31(2.6 \%)$ & & \\
\hline 2 & $7(1.5 \%)$ & $19(1.6 \%)$ & & \\
\hline$\geqslant 3$ & $33(7.1 \%)$ & $87(7.4 \%)$ & & \\
\hline \multicolumn{5}{|l|}{ LAMA prescriptions } \\
\hline 0 & $139(29.8 \%)$ & $343(29.0 \%)$ & 0.001 & 13.9 \\
\hline $1-3$ & $89(19.1 \%)$ & $213(18.0 \%)$ & & \\
\hline $4-6$ & $81(17.4 \%)$ & $135(11.4 \%)$ & & \\
\hline $7-9$ & $56(12.0 \%)$ & $124(10.5 \%)$ & & \\
\hline $10-12$ & $63(13.5 \%)$ & $216(18.3 \%)$ & & \\
\hline$\geqslant 13$ & $38(8.2 \%)$ & $150(12.7 \%)$ & & \\
\hline \multicolumn{5}{|l|}{ Average daily OCS dose } \\
\hline$<2.5 \mathrm{mg}$ & $379(81.3 \%)$ & $983(83.2 \%)$ & 0.433 & 1.2 \\
\hline$\geqslant 2.5-<5 \mathrm{mg}$ & $52(11.2 \%)$ & $112(9.5 \%)$ & & \\
\hline
\end{tabular}




\begin{tabular}{|c|c|c|c|c|}
\hline & LAMA/LABA $(n=466)$ & $\begin{array}{l}\text { Triple therapy } \\
\text { (n=1181) }\end{array}$ & p-value & SMD \\
\hline$\geqslant 5-<7.5 \mathrm{mg}$ & $18(3.9 \%)$ & $31(2.6 \%)$ & & \\
\hline$\geqslant 7.5 \mathrm{mg}$ & $16(3.4 \%)$ & $49(4.1 \%)$ & & \\
\hline $5 \mathrm{mg}$ & $0(0.0 \%)$ & $4(0.3 \%)$ & & \\
\hline $6 \mathrm{mg}$ & $1(0.2 \%)$ & $2(0.2 \%)$ & & \\
\hline \multicolumn{5}{|l|}{$\begin{array}{l}\text { Acute respiratory events in baseline } \\
\text { year }\end{array}$} \\
\hline 0 & $22(4.7 \%)$ & $53(4.5 \%)$ & 0.797 & 5.0 \\
\hline 1 & $48(10.3 \%)$ & $116(9.8 \%)$ & & \\
\hline 2 & $90(19.3 \%)$ & $200(16.9 \%)$ & & \\
\hline 3 & $96(20.6 \%)$ & $256(21.7 \%)$ & & \\
\hline$\geqslant 4$ & $210(45.1 \%)$ & $556(47.1 \%)$ & & \\
\hline \multicolumn{5}{|l|}{ Exacerbations in baseline year" } \\
\hline 2 & $287(61.6 \%)$ & $698(59.1 \%)$ & 0.718 & 3.4 \\
\hline 3 & $105(22.5 \%)$ & $284(24.0 \%)$ & & \\
\hline 4 & $34(7.3 \%)$ & $101(8.6 \%)$ & & \\
\hline$\geqslant 5$ & $40(8.6 \%)$ & $98(8.3 \%)$ & & \\
\hline \multicolumn{5}{|l|}{$\begin{array}{l}\text { Acute OCS courses in baseline } \\
\text { year }^{\#}\end{array}$} \\
\hline 0 & $95(20.4 \%)$ & $234(19.8 \%)$ & 0.700 & 1.7 \\
\hline 1 & $117(25.1 \%)$ & $328(27.8 \%)$ & & \\
\hline$\geqslant 2$ & $254(54.5 \%)$ & $619(52.4 \%)$ & & \\
\hline \multicolumn{5}{|l|}{ Antibiotic courses in baseline year ${ }^{\#}$} \\
\hline 0 & $80(17.2 \%)$ & $202(17.1 \%)$ & 0.627 & 2.9 \\
\hline 1 & $115(24.7 \%)$ & $296(25.1 \%)$ & & \\
\hline 2 & $183(39.3 \%)$ & $435(36.8 \%)$ & & \\
\hline 3 & $63(13.5 \%)$ & $165(14.0 \%)$ & & \\
\hline 4 & $13(2.8 \%)$ & $55(4.7 \%)$ & & \\
\hline$\geqslant 5$ & $12(2.6 \%)$ & $28(2.4 \%)$ & & \\
\hline GOLD severity (\% nonmissing) & $373(80.0 \%)$ & $957(81.0 \%)$ & 0.394 & 8.0 \\
\hline Mild, FEV $1>80 \%$ predicted & $44(11.8 \%)$ & $105(11.0 \%)$ & & \\
\hline Moderate, FEV $150-80 \%$ predicted & $190(50.9 \%)$ & $447(46.7 \%)$ & & \\
\hline Severe, FEV $130-50 \%$ predicted & $94(25.2 \%)$ & $281(29.4 \%)$ & & \\
\hline Very severe, FEV $1<30 \%$ predicted & $45(12.1 \%)$ & $124(13.0 \%)$ & & \\
\hline GOLD risk group $n$ ( $\%$ nonmissing) & $389(83.5 \%)$ & $976(82.6 \%)$ & 0.187 & 7.9 \\
\hline $\mathrm{C}$ & $236(60.7 \%)$ & $554(56.8 \%)$ & & \\
\hline $\mathrm{D}$ & $153(39.3 \%)$ & $422(43.2 \%)$ & & \\
\hline mMRC score $\mathrm{n}$ (\% nonmissing) & $389(83.5 \%)$ & $976(82.6 \%)$ & 0.671 & 5.7 \\
\hline 0 , not troubled by breathlessness & $37(9.5 \%)$ & $98(10.0 \%)$ & & \\
\hline 1 , short of breath & $199(51.2 \%)$ & $456(46.7 \%)$ & & \\
\hline 2, slower in walking & $96(24.7 \%)$ & $266(27.3 \%)$ & & \\
\hline 3 , stopping for breath & $49(12.6 \%)$ & $131(13.4 \%)$ & & \\
\hline 4 , too breathless to leave the house & $8(2.1 \%)$ & $25(2.6 \%)$ & & \\
\hline
\end{tabular}

Data are presented as mean $\pm \mathrm{SD} /$ median (interquartile range) unless otherwise stated. LAMA: long-acting muscarinic antagonist; LABA: long-acting inhaled B-agonist; SMD: standardised mean difference; IQR: interquartile range; BMI: body mass index; SABA: short-acting inhaled B-agonist; SAMA: short-acting muscarinic antagonist; LAMA: long-acting muscarinic antagonist; OCS: oral corticosteroid; GOLD: Global Initiative for Chronic Obstructive Lung Disease; FEV1: forced expiratory volume in $1 \mathrm{~s}$; mMRC: modified Medical Research Council dyspnoea scale. "\#includes the index date; ${ }^{\text {I: }}$ symptom and risk based. p-values are for the Kruskal-Wallis equality-of-populations rank test or Pearson's Chi-squared test of independent categories, where appropriate.

\section{Unadjusted IRRs}

For the primary outcome (time to first exacerbation), the average duration of follow-up per patient was 0.74 and 0.87 years in the TT and DB arms, respectively. The incidence rate of a first exacerbation in the outcome period was lower in the TT arm (0.79/patient-year) compared with the DB arm (0.91), equating to an unadjusted IRR of 0.87 (95\% CI 0.76-0.99; table 4). The IRRs for time to an acute respiratory event and treatment failure were also in favour of TT, as were those for time until first acute OCS course and first antibiotics course, although the differences for the latter two outcomes were not statistically significant (table 4). 
TABLE 3 Number of patients improving or worsening from baseline to the first outcome year, matched

\begin{tabular}{|c|c|c|c|c|c|c|c|}
\hline & \multicolumn{2}{|c|}{ Improved } & \multicolumn{2}{|c|}{ Unchanged } & \multicolumn{2}{|c|}{ Worsened } & NNE \\
\hline Exacerbations & 225 (73.5\%) & $651(78.2 \%)$ & $41(13.4 \%)$ & $96(11.5 \%)$ & $40(13.1 \%)$ & $85(10.2 \%)$ & 21 \\
\hline Acute respiratory events & $173(56.5 \%)$ & 550 (66.1\%) & $51(16.7 \%)$ & $123(14.8 \%)$ & $82(26.8 \%)$ & $159(19.1 \%)$ & 10 \\
\hline Acute OCS courses & $158(51.6 \%)$ & 494 (59.4\%) & $98(32.0 \%)$ & $213(25.6 \%)$ & $50(16.3 \%)$ & $125(15.0 \%)$ & 15 \\
\hline Antibiotics courses & $193(63.1 \%)$ & $523(62.9 \%)$ & $72(23.5 \%)$ & $218(26.2 \%)$ & $41(13.4 \%)$ & $91(10.9 \%)$ & 134 \\
\hline mMRC score & $32(16.7 \%)$ & $32(6.1 \%)$ & $101(52.6 \%)$ & $264(50.2 \%)$ & $59(30.7 \%)$ & $163(31.0 \%)$ & \\
\hline
\end{tabular}

\section{Multivariable outcome models}

The effect sizes of TT versus DB for the outcomes of interest are presented in table 5. All time-to-event adjusted analyses results were in favour of TT. A significantly reduced risk in favour of TT was seen for the primary outcome of first exacerbation (HR $0.87,95 \%$ CI $0.76-0.99$ ). Among the secondary outcomes, first acute respiratory event (HR $0.74,95 \%$ CI $0.66-0.84$ ) and treatment failure (HR $0.83,95 \%$ CI 0.73-0.95) were significantly in favour of TT after statistical adjustment and correction for multiple testing. A reduced risk in favour of TT was also seen for first acute OCS course and first antibiotics course, but these did not reach significance. Results of the conditional negative binomial regression showed significantly lower acute OCS courses rate (rate ratio (RR) $0.80,95 \%$ CI $0.66-0.98$ ) and acute respiratory events rate (RR $0.79,95 \%$ CI $0.70-0.90$ ) in the TT group. The effect sizes in the sensitivity analyses using IPTW were similar to the time-to-event models (data not shown) as were the results after excluding patients with a history of asthma (for some outcomes a slightly stronger effect was seen; supplementary table 6).

\section{Effect modification}

The results presented below are based on the investigation of the effect of the number of previous exacerbations and baseline BEC as continuous variables. On visual inspection, the results using the categorical representation of these potential effect modifiers did not show a meaningful difference with the

TABLE 4 Unadjusted incidence rate (IR) ratios for time-to-event outcomes, by matched treatment cohort

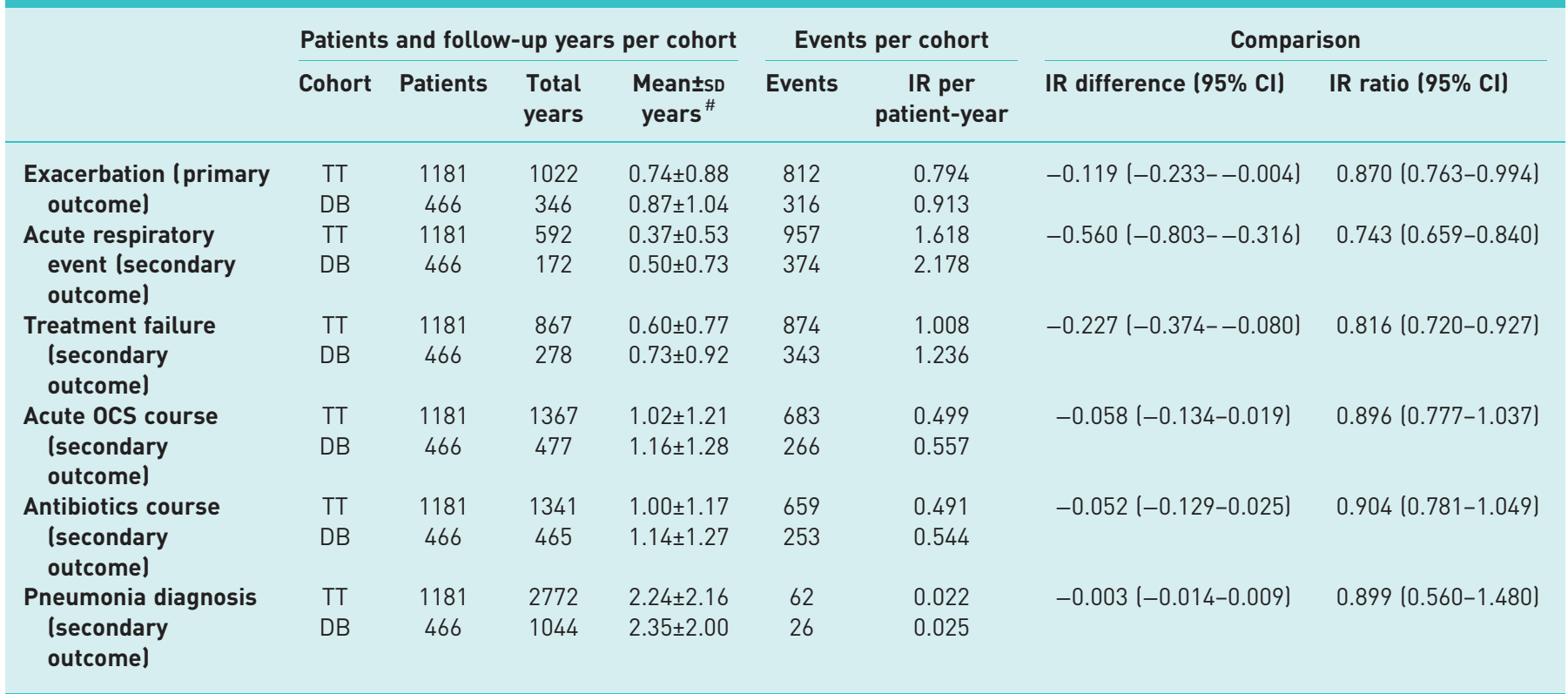

OCS: oral corticosteroid; TT: triple therapy; DB: dual bronchodilation with long-acting muscarinic antagonist/long-acting inhaled B-agonist. ${ }^{\#}$ : mean follow-up time in years available. 


\begin{tabular}{|c|c|c|c|c|c|}
\hline \multirow[t]{2}{*}{ Outcome } & \multirow[t]{2}{*}{ Patients } & \multicolumn{2}{|c|}{ Unadjusted } & \multicolumn{2}{|c|}{ Adjusted } \\
\hline & & $\operatorname{HR}(95 \% \mathrm{CI})$ & p-value & $\operatorname{HR}(95 \% \mathrm{CI})$ & p-value \\
\hline First exacerbation & 1647 & $0.90(0.79-1.02)$ & 0.111 & $0.87(0.76-0.99)$ & 0.040 \\
\hline First acute respiratory event & 1647 & $0.79(0.70-0.88)$ & $<0.001 *$ & $0.74(0.66-0.84)$ & $<0.001^{*}$ \\
\hline Treatment failure & 1647 & $0.86(0.76-0.98)$ & 0.020 & $0.83(0.73-0.95)$ & $0.005^{*}$ \\
\hline First acute OCS course & 1647 & $0.95(0.82-1.09)$ & 0.437 & $0.93(0.80-1.07)$ & 0.298 \\
\hline First antibiotics course & 1647 & $0.91(0.79-1.04)$ & 0.171 & $0.89(0.77-1.04)$ & 0.138 \\
\hline \multirow[t]{2}{*}{ Pneumonia diagnosis } & 1647 & $1.26(0.80-1.98)$ & 0.325 & $0.71(0.21-2.38)$ & 0.573 \\
\hline & & $\operatorname{RR}(95 \% \mathrm{CI})$ & p-value & $\operatorname{RR}(95 \% \mathrm{CI})$ & p-value \\
\hline Exacerbation rate & 1138 & $0.85(0.73-1.00)$ & 0.056 & $0.86(0.73-1.01)$ & 0.068 \\
\hline Acute OCS courses rate & 1138 & $0.83(0.68-1.01)$ & 0.067 & $0.80(0.66-0.98)$ & 0.030 \\
\hline Antibiotics courses rate & 1138 & $0.88(0.72-1.06)$ & 0.183 & $0.91(0.75-1.10)$ & 0.332 \\
\hline \multirow[t]{2}{*}{ Acute respiratory events rate } & 1138 & $0.80(0.70-0.90)$ & $<0.001$ & $0.79(0.70-0.90)$ & $<0.001 *$ \\
\hline & & OR $(95 \% \mathrm{CI})$ & p-value & $\operatorname{RR}(95 \% \mathrm{CI})$ & p-value \\
\hline $\mathrm{mMRC} \geqslant 2$ & 885 & $1.20(0.86-1.68)$ & 0.293 & $1.12(0.76-1.66)$ & 0.566 \\
\hline
\end{tabular}

HR: hazard ratio; OCS: oral corticosteroid; mMRC: modified Medical Research Council dyspnoea scale; RR: rate ratio. *: $p<0.05$ after controlling for 10 statistical tests for secondary outcomes performed following Holm's method [22].

results using the continuous modifiers. This was confirmed by the model fit statistics. The differences in Akaike's information criterion (AIC) and Bayesian information criterion (BIC), which take the number of parameters introduced by categorical variables into account, show no evidence of better fit (lower AIC or BIC) with the use of categorical variables (supplementary table 7).

The number of exacerbations in the baseline year showed significant effect modification with the primary outcome (time to the first exacerbation) and with the secondary outcomes of time to the first acute respiratory event and OCS course (figure 3a and supplementary table 8). The higher the exacerbation rate in the baseline year, the greater the risk reduction for a future outcome in the TT initiators compared with the DB initiators. After controlling for multiple testing, significant effect modification was found for the time to the first acute respiratory event. The HR was 0.79 (95\% CI $0.66-0.95$ ) for patients with two exacerbations compared with 0.19 (95\% CI 0.04-0.87) for patients with five exacerbations in the baseline year.

The baseline BEC modified the effect of the comparison significantly for all time to the first event outcomes, except time to the first antibiotics course (figure $3 \mathrm{~b}$ and supplementary table 9). After controlling for multiple testing, significant effect modification was found for the time to the first acute OCS course prescribed. At a count $<0.05 \times 10^{9}$ cells $\cdot \mathrm{L}^{-1}$ the effect was in favour of DB (HR $1.24,95 \%$ CI 1.01-1.53), and from a count of $0.35 \times 10^{9}$ cells $\cdot \mathrm{L}^{-1}$ onwards TT showed a significantly greater risk-reducing effect than DB.

The level of airflow limitation, GOLD risk group, and the number of nonrespiratory drugs prescribed did not show significant effect modification with any of the study outcomes (supplementary figure 3 ).

\section{Discussion}

Our study shows that stepping-up from no prior maintenance therapy or LAMA monotherapy for COPD to TT was associated with a greater reduction in the risk of exacerbation, acute respiratory event and treatment failure than to a DB therapy in the study population. This association in favour of TT was significantly greater for patients with higher rates of exacerbations in the year prior to step-up. TT was also associated with a lower risk of outcome events than DB in patients with a higher BEC. However, we did not find a significant difference in benefit from TT by GOLD severity and risk group. If this observation is true, and not caused by limited power, this could be likely due to the existence of COPD phenotypes with lower responsiveness within the higher risk GOLD group D. In both unadjusted IRR analysis and multivariate outcome model analysis, rates of pneumonia in both treatment groups were similar and not significantly different. 
a)

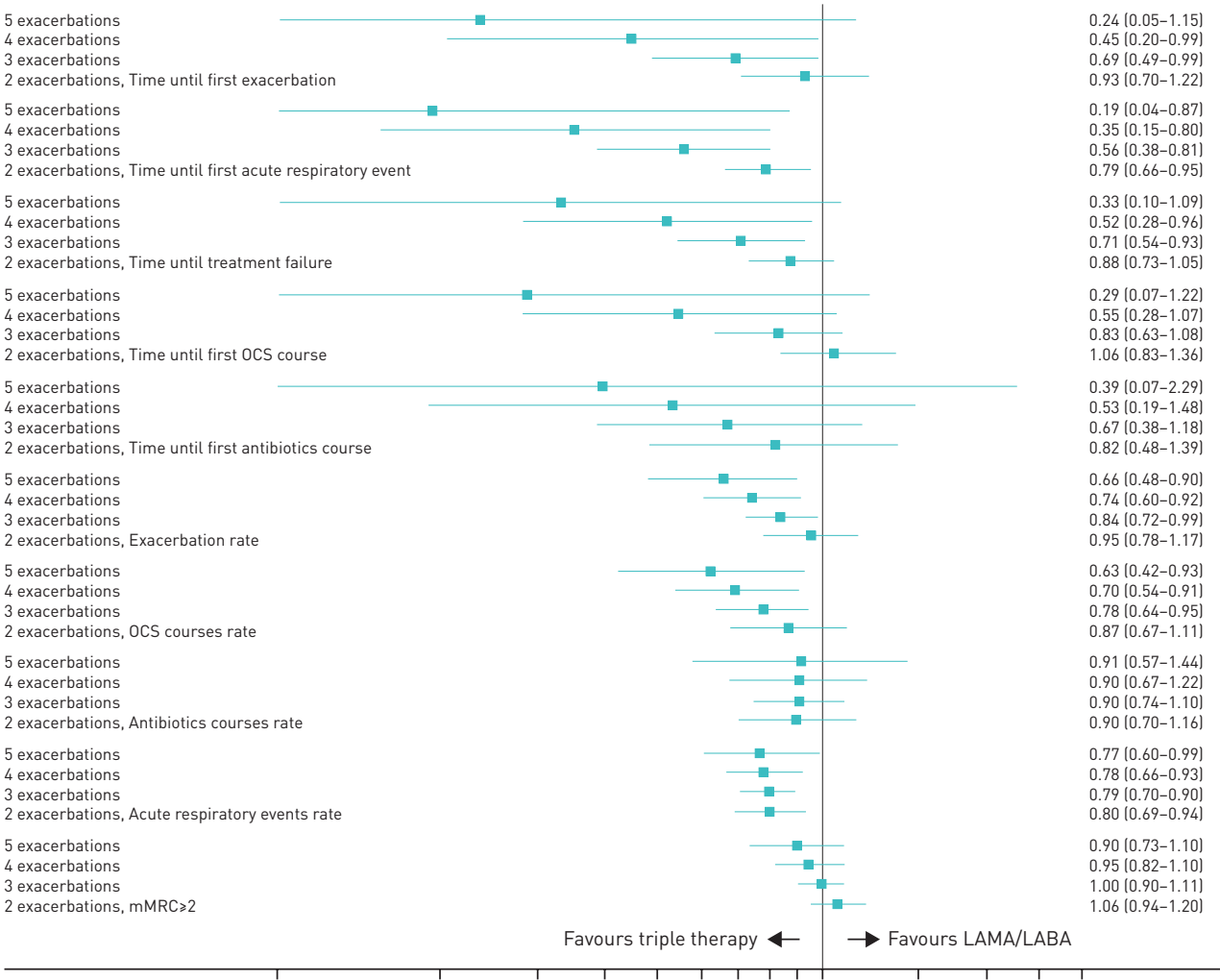

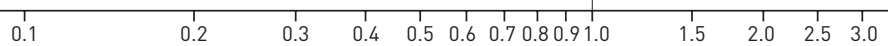

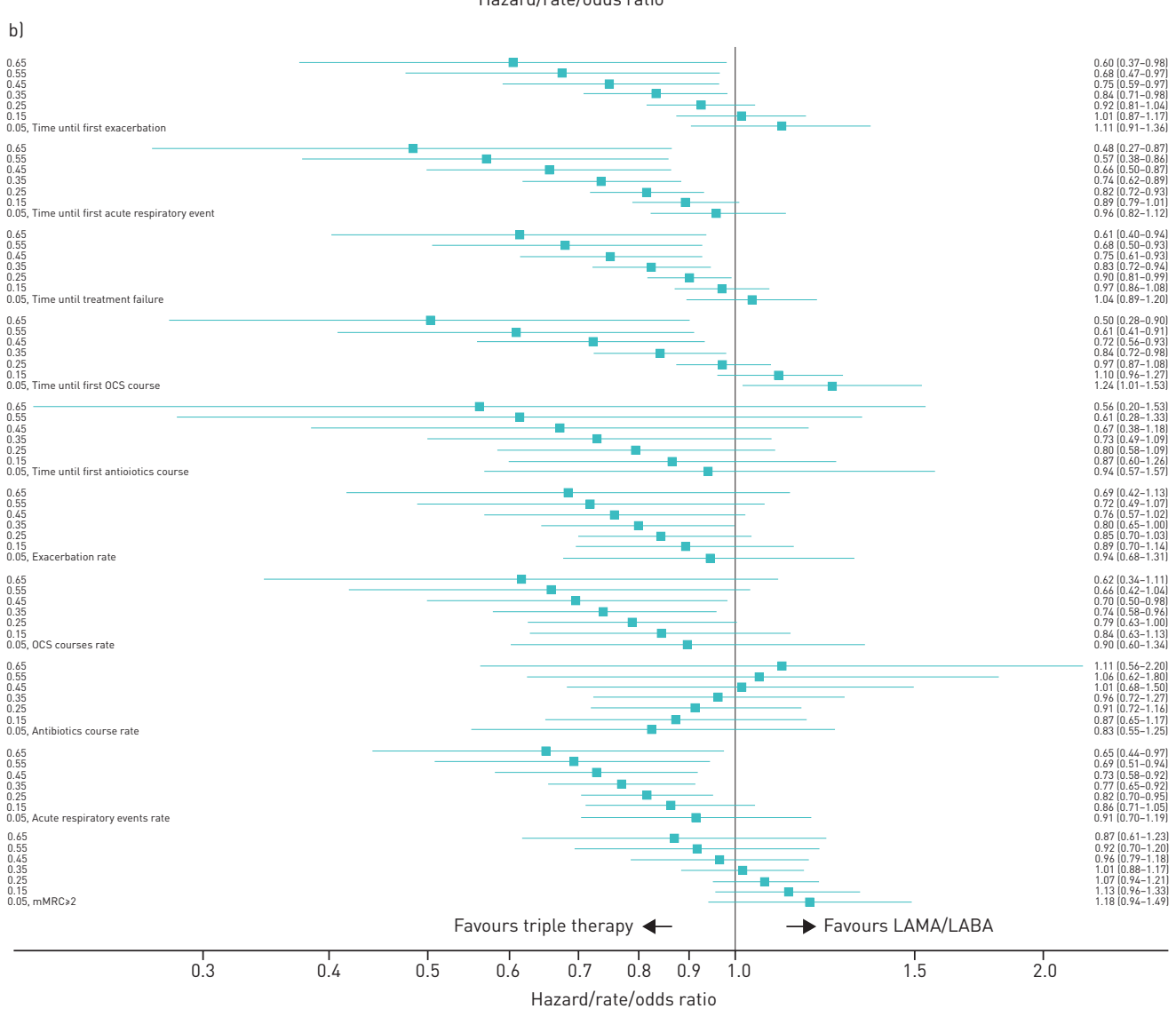

FIGURE 3 a) Effect modification by number of exacerbations in the baseline year. b) Effect modification by baseline blood eosinophil count. LAMA: long-acting muscarinic antagonist; LABA: long-acting inhaled B-agonist. 
Real-world evidence has been scarce on the comparative effectiveness of TT versus DB for COPD. Results from two recently published RCTs showed significantly larger reduction in rate of exacerbations with TT compared with DB therapy in selected COPD populations $[9,10]$. There are however limitations inherent to clinical trials. Participants are usually younger and not as severely ill as might be expected. Thus, they are not fully representative of the real-world population the therapy would target. Also, different inclusion and exclusion criteria are used for various clinical trials which complicates interpretation of data. Therefore, it is important to supplement the findings of trials with evidence from observational studies. Our timely real-world study complements and adds to the growing body of evidence in favour of TT for some COPD patient populations.

A recent real-life study compared the treatment effectiveness of TT to DB using patients in the DACCORD cohort [24]. In contrast to our study, they reported fewer exacerbations among patients who received DB than TT. This might be due to the difference in patient population between both studies. Our study includes patients with at least two exacerbations in the baseline year while $>70 \%$ patients in DACCORD had no exacerbation 6 months prior to study entry. As shown in the current study, patients with higher baseline exacerbation have a greater benefit from TT. In addition, the previous study also included patients who remained with their therapy, while we included patients who had no maintenance therapy or only LAMA monotherapy at baseline.

Our study has many strengths. Firstly, we included only a population of patients who stepped-up to either DB or TT and excluded patients with evidence of active asthma, asthma-COPD overlap syndrome, and those prescribed the therapy under study at any point during the baseline year. Some RCTs have also included patients in the DB group stepping down in their treatment from TT. The abrupt withdrawal of ICSs during randomisation in these patients could have led to COPD exacerbations and thus exaggerated the benefit of TT evident in the trial $[10,25,26]$. Secondly, we selected a homogeneous population of patients who would be eligible for TT treatment according to GOLD recommendations, i.e. those who had two or more exacerbations in the baseline year. Thirdly, we have examined effect modifiers to help identify possible subgroups of patients that might benefit more from a treatment. In this study, patients with a higher number of exacerbations in the baseline year and patients with a higher BEC had more benefit from TT. Fourthly, the treatment groups we compared had well-balanced baseline characteristics after matching and any residual measured confounding was accounted for in the analyses. Although we cannot fully exclude residual bias by indication due to unmeasured characteristics, the risk of residual bias from differences in COPD severity is likely to be small due to the availability of detailed information. Finally, sensitivity analyses showed that restriction of the patient population during matching did not affect results of time-to-event models. The exclusion of patients with a prior history of asthma gave similar results (or a slightly stronger effect) meaning that the observed effects were not attributable to asthma.

Some limitations however also need consideration. We may have underestimated the relative effectiveness of TT as we performed an intention-to-treat analysis without considering a step-up to TT in the DB group during follow-up, which occurred in a third of patients. Also, our study was based only on multi-inhaler TT whereas today, two fixed-dose single-inhaler TTs are available on the market [27], with a possible benefit on adherence. On the other hand, $38.4 \%$ patients on DB were initiated on a single inhaler. Another limitation of our study is that despite the large numbers of patients with COPD in the databases, we did not achieve sufficient statistical power for analysing outcomes with low incident rates, such as pneumonia. This is partly due to fact that DB has only recently been introduced as an alternative treatment option in guidelines.

In conclusion, this real-world observational study found that TT was associated with a significantly greater reduction in exacerbation risk and risk of other outcomes compared with DB in patients with a history of at least two exacerbations in the previous year. The risk reduction effect for secondary outcomes, including acute respiratory events and prescription of an acute OCS course, increased with prior exacerbation rate and baseline BEC. Our results add to the emerging body of evidence in favour of TT over DB in patients with frequent exacerbations in the management of COPD.

Acknowledgements: Writing and editorial support was provided by Julia Granerod, supported by the Observational and Pragmatic Research Institute Pte. Ltd.

Conflict of interest: J. Voorham was employed by OPRI, which has conducted paid research in respiratory disease on behalf of the following organisations in the past 5 years: Anaxys, AstraZeneca, Boehringer Ingelheim, British Lung Foundation, Chiesi, Circassia (formerly Aerocrine), GlaxoSmithKline, Harvey Walsh, Mapi, Morningside Healthcare, Mundipharma, Mylan (formerly Meda), Napp, Novartis, Orion, Plymouth University, Regeneron, Respiratory Effectiveness Group, Roche, Sanofi, Takeda, Teva, University of East Anglia, Zentiva (a Sanofi company). M. Corradi reports grants and personal fees from Chiesi Farmaceutici, outside the submitted work. A. Papi reports board membership, consultancy, payment for lectures, grants for research and travel expenses reimbursement from Chiesi, AstraZeneca, GlaxoSmithKline and Boehringer Ingelheim; payment for lectures and travel expenses reimbursement from 
Menarini, Novartis and Zambon; board membership, payment for lectures, grants for research and travel expenses reimbursement from Pfizer; Board membership, consultancy, payment for lectures and travel expenses reimbursement from Mundipharma; board membership, consultancy, payment for lectures, grants for research and travel expenses reimbursement from Teva; and grants for research from Sanofi, outside the submitted work. C.F. Vogelmeier reports personal fees from Almirall, Cipla, Berlin Chemie/Menarini, CSL Behring and Teva, grants and personal fees from AstraZeneca, Boehringer Ingelheim, Chiesi, GlaxoSmithKline, Grifols, Mundipharma, Novartis and Takeda, and grants from the German Federal Ministry of Education and Research (BMBF) Competence Network Asthma and COPD (ASCONET), Bayer Schering Pharma AG, MSD and Pfizer, outside the submitted work. D. Singh reports grants and personal fees from AstraZeneca, Boehringer Ingelheim, Chiesi, GlaxoSmithKline, Glenmark, Menarini, Mundipharma, Novartis, Pfizer, Pulmatrix, Therevance and Verona, and personal fees from Cipla, Genentech and Peptinnovate, outside the submitted work. L.M. Fabbri reports personal fees and nonfinancial support from AstraZeneca, Chiesi, GSK, Novartis, Menarini, Boehringer Ingelheim, Zambon and Pearl Therapeutics, and personal fees from Teva and Verona Pharma, outside the submitted work. M. Kerkhof was employed by OPRI, which has conducted paid research in respiratory disease on behalf of the following organizations in the past 5 years: Anaxys, AstraZeneca, Boehringer Ingelheim, British Lung Foundation, Chiesi, Circassia (formerly Aerocrine), GlaxoSmithKline, Harvey Walsh, Mapi, Morningside Healthcare, Mundipharma, Mylan (formerly Meda), Napp, Novartis, Orion, Plymouth University, Regeneron, Respiratory Effectiveness Group, Roche, Sanofi, Takeda, Teva, University of East Anglia, Zentiva (a Sanof company). J.H. Kocks was employed by OPRI, which has conducted paid research in respiratory disease on behalf of the following organizations in the past 5 years: Anaxys, AstraZeneca, Boehringer Ingelheim, British Lung Foundation, Chiesi, Circassia (formerly Aerocrine), GlaxoSmithKline, Harvey Walsh, Mapi, Morningside Healthcare, Mundipharma, Mylan (formerly Meda), Napp, Novartis, Orion, Plymouth University, Regeneron, Respiratory Effectiveness Group, Roche, Sanofi, Takeda, Teva, University of East Anglia, Zentiva (a Sanofi company). V. Carter was employed by OPRI, which has conducted paid research in respiratory disease on behalf of the following organizations in the past 5 years: Anaxys, AstraZeneca, Boehringer Ingelheim, British Lung Foundation, Chiesi, Circassia (formerly Aerocrine), GlaxoSmithKline, Harvey Walsh, Mapi, Morningside Healthcare, Mundipharma, Mylan (formerly Meda), Napp, Novartis, Orion, Plymouth University, Regeneron, Respiratory Effectiveness Group, Roche, Sanofi, Takeda, Teva, University of East Anglia, Zentiva (a Sanofi company). D. Price reports grants and unrestricted funding for investigator-initiated studies (conducted through Observational and Pragmatic Research Institute), board membership and payment for travel/accommodation/meeting expenses (fees paid to Observational and Pragmatic Research Institute) from Aerocrine; grants and unrestricted funding for investigator-initiated studies (conducted through Observational and Pragmatic Research Institute) from AKL Research and Development Ltd; consultancy agreements and lectures/speaking engagements (fees paid to Observational and Pragmatic Research Institute) from Almirall; board membership and consultancy agreements (fees paid to Observational and Pragmatic Research Institute) from Amgen; grants and unrestricted funding for investigator-initiated studies (conducted through Observational and Pragmatic Research Institute), board membership, consultancy agreements, lectures/speaking engagements and payment for travel/ accommodation/meeting expenses (fees paid to Observational and Pragmatic Research Institute) from AstraZeneca; grants and unrestricted funding for investigator-initiated studies (conducted through Observational and Pragmatic Research Institute), board membership, consultancy agreements, lectures/speaking engagements and payment for travel/ accommodation/meeting expenses (fees paid to Observational and Pragmatic Research Institute) from Boehringer Ingelheim; grants and unrestricted funding for investigator-initiated studies (conducted through Observational and Pragmatic Research Institute) from British Lung Foundation; Grants and unrestricted funding for investigator-initiated studies (conducted through Observational and Pragmatic Research Institute). Board membership; Consultancy agreements; lectures/speaking engagements and funding for patient enrolment or completion of research (fees paid to Observational and Pragmatic Research Institute) from Chiesi; lectures/speaking engagements (fees paid to Observational and Pragmatic Research Institute) from Cipla; consultancy agreements and lectures/speaking engagements (fees paid to Observational and Pragmatic Research Institute) from GlaxoSmithKline; lectures/speaking engagements (fees paid to Observational and Pragmatic Research Institute) from Kyorin; lectures/speaking engagements (fees paid to Observational and Pragmatic Research Institute) from Merck; grants and unrestricted funding for investigator-initiated studies (conducted through Observational and Pragmatic Research Institute), board membership, consultancy agreements and lectures/speaking engagements (fees paid to Observational and Pragmatic Research Institute) from Mylan; grants and unrestricted funding for investigator-initiated studies (conducted through Observational and Pragmatic Research Institute), board membership, consultancy agreements, lectures/speaking engagements, manuscript preparation, payment for travel/accommodation/meeting expenses and payment for the development of educational materials (fees paid to Observational and Pragmatic Research Institute) from Mundipharma; grants and unrestricted funding for investigator-initiated studies (conducted through Observational and Pragmatic Research Institute), board membership, consultancy agreements, payment for travel/accommodation/meeting expenses (fees paid to Observational and Pragmatic Research Institute) from Napp; grants and unrestricted funding for investigator-initiated studies (conducted through Observational and Pragmatic Research Institute), board membership, consultancy agreements, lectures/speaking engagements, payment for travel/accommodation/meeting expenses, funding for patient enrolment or completion of research and payment for the development of educational materials (fees paid to Observational and Pragmatic Research Institute) from Novartis; grants and unrestricted funding for investigator-initiated studies (conducted through Observational and Pragmatic Research Institute), consultancy agreements, lectures/speaking engagements (fees paid to Observational and Pragmatic Research Institute) from Pfizer; board membership, grants and unrestricted funding for investigator-initiated studies (conducted through Observational and Pragmatic Research Institute Pte Ltd) and lectures/speaking engagements (fees paid to Observational and Pragmatic Research Institute) from Regeneron Pharmaceuticals; grants and unrestricted funding for investigator-initiated studies (conducted through Observational and Pragmatic Research Institute) from Respiratory Effectiveness Group; board membership, grants and unrestricted funding for investigator-initiated studies (conducted through Observational and Pragmatic Research Institute Pte Ltd) and lectures/speaking engagements (fees paid to Observational and Pragmatic Research Institute) from Sanofi Genzyme; lectures/speaking engagements (fees paid to Observational and Pragmatic Research Institute) from Skyepharma; grants and unrestricted funding for investigator-initiated studies (conducted through Observational and Pragmatic Research Institute), board membership, consultancy agreements, lectures/speaking engagements, manuscript preparation, payment for travel/accommodation/meeting expenses and funding for patient enrolment or completion of research (fees paid to Observational and Pragmatic Research Institute) from Teva; grants and unrestricted funding for 
investigator-initiated studies (conducted through Observational and Pragmatic Research Institute) and consultancy agreements (fees paid to Observational and Pragmatic Research Institute) from Theravance; grants and unrestricted funding for investigator-initiated studies (conducted through Observational and Pragmatic Research Institute) from UK National Health Service; grants and unrestricted funding for investigator-initiated studies (conducted through Observational and Pragmatic Research Institute) and funding for patient enrolment or completion of research (fees paid to Observational and Pragmatic Research Institute) from Zentiva (Sanofi Generics); and acting as a peer reviewer for grant committees for Efficacy and Mechanism Evaluation programme and Health Technology Assessment, outside the submitted work; and stock/stock options from AKL Research and Development Ltd, which produces phytopharmaceuticals; and owning 74\% of the social enterprise Optimum Patient Care Ltd (Australia and UK) and 74\% of Observational and Pragmatic Research Institute Pte Ltd (Singapore).

Support statement: This study was funded by Chiesi Farmaceutici, S.p.A. Funding information for this article has been deposited with the Crossref Funder Registry.

\section{References}

1 Global Initiative for Chronic Obstructive Lung Disease. Global strategy for the diagnosis, management, and prevention of chronic obstructive pulmonary disease 2018. www.goldcopd.org.

2 Vogelmeier CF, Criner GJ, Martinez FJ, et al. Global strategy for the diagnosis, management, and prevention of chronic obstructive lung disease 2017 report: GOLD executive summary. Eur Respir J 2017; 49: 1700214.

3 Suissa S. Number needed to treat in COPD: exacerbations versus pneumonias. Thorax 2013; 68: 540-543.

4 Price D, Yawn B, Brusselle G, et al. Risk-to-benefit ratio of inhaled corticosteroids in patients with COPD. Prim Care Respir J 2013; 22: 92-100.

5 Vestbo J, Vogelmeier C, Small M, et al. Understanding the GOLD 2011 strategy as applied to a real-world COPD population. Respir Med 2014; 108: 729-736.

6 Price D, West D, Brusselle G, et al. Management of COPD in the UK primary-care setting: an analysis of real-life prescribing patterns. Int J Chron Obstruct Pulmon Dis 2014; 9: 889-904.

7 Singh D, Papi A, Corradi M, et al. Single inhaler triple therapy versus inhaled corticosteroid plus long-acting beta2-agonist therapy for chronic obstructive pulmonary disease (TRILOGY): a double-blind, parallel group randomised controlled trial. Lancet 2016; 388: 963-973.

8 Lipson DA, Barnacle H, Birk R, et al. FULFIL trial: once-daily triple therapy for patients with chronic obstructive pulmonary disease. Am J Respir Crit Care Med 2017; 196: 438-446.

9 Papi A, Vestbo J, Fabbri L, et al. Extrafine inhaled triple therapy versus dual bronchodilator therapy in chronic obstructive pulmonary disease (TRIBUTE): a double-blind, parallel group, randomised controlled trial. Lancet 2018; 391: 1076-1084

10 Lipson DA, Barnhart F, Brealey N, et al. Once-daily single-inhaler triple versus dual therapy in patients with COPD. N Eng J Med 2018; 378: 1671-1680.

11 Siddiqui SH, Pavord ID, Barnes NC, et al. Blood eosinophils: a biomarker of COPD exacerbation reduction with inhaled corticosteroids. Int J Chron Obstruct Pulmon Dis 2018; 13: 3669-3676.

12 Gaebel K, McIvor RA, Xie F, et al. Triple therapy for the management of COPD: a review. COPD 2011; 8 206-243

13 Short PM, Williamson PA, Elder DHJ, et al. The impact of tiotropium on mortality and exacerbations when added to inhaled corticosteroids and long-acting beta-agonist therapy in COPD. Chest 2012; 141: 81-86.

14 Belhassen M, Nibber A, Van Ganse E, et al. Inappropriate asthma therapy-a tale of two countries: a paralle population-based cohort study. NPJ Prim Care Respir Med 2016; 26: 16076.

15 Halpin DM, Kerkhof M, Soriano JB, et al. Eligibility of real-life patients with COPD for inclusion in trials of inhaled long-acting bronchodilator therapy. Respir Res 2016; 17: 120.

16 Herrett E, Gallagher AM, Bhaskaran K, et al. Data resource profile: Clinical Practice Research Datalink (CPRD) Int J Epidemiol 2015; 44: 827-836.

17 Quint JK, Müllerova H, DiSantostefano RL, et al. Validation of chronic obstructive pulmonary disease recording in the clinical practice research datalink (CPRD-GOLD). BMJ Open 2014; 4: e005540.

18 Rothnie KJ, Mullerova H, Hurst JR, et al. Validation of the recording of acute exacerbations of COPD in UK primary care electronic healthcare records. PLoS One 2016; 11: e0151357.

19 Austin PC. An introduction to propensity score methods for reducing the effects of confounding in observational studies. Multivariate Behav Res 2011; 46: 399-424.

20 Rosenbaum PR, Rubin DB. Constructing a control group using multivariate matched sampling methods that incorporate the propensity score. Am Stat 1985; 39: 33-38.

21 Guyatt GH, Juniper EF, Walter SD, et al. Interpreting treatment effects in randomised trials. BMJ 1998; 316 690-693.

22 Holm S. A simple sequentially rejective multiple test procedure. Scand J Stat 1979; 6: 65-70.

23 Price DB, Baker CL, Zou KH, et al. Real-world characterization and differentiation of the Global Initiative for Chronic Obstructive Lung Disease strategy classification. Int J Chron Obstruct Pulmon Dis 2014; 9: 551-561.

24 Buhl R, Criee CP, Kardos P, et al. Dual bronchodilation vs triple therapy in the "real-life" COPD DACCORD study. Int J Chron Obstruct Pulmon Dis 2018; 13: 2557-2568.

25 Wedzicha JA, Banerji D, Chapman KR, et al. Indacaterol-glycopyrronium versus salmeterol-fluticasone for COPD. N Engl J Med 2016; 374: 2222-2234.

26 Wedzicha JA, Decramer M, Ficker JH, et al. Analysis of chronic obstructive pulmonary disease exacerbations with the dual bronchodilator QVA149 compared with glycopyrronium and tiotropium (SPARK): a randomised, double-blind, parallel-group study. Lancet Respir Med 2013; 1: 199-209.

27 Ga duzo S, McGovern V, Roberts J, et al. When to use single-inhaler triple therapy in COPD: a practical approach for primary care health care professionals. Int J Chron Obstruct Pulmon Dis 2019; 14: 391-401. 